\title{
A COMPETÊNCIA EM INFORMAÇÃO E MIDIÁTICA VOLTADA À CIDADANIA: O USO DA INFORMAÇÃO GOVERNAMENTAL PARA A PARTICIPAÇÃO NA DEMOCRACIA
}

INFORMATION LITERACY AND MEDIA COMPETENCE FOCUSED ON CITIZENSHIP: THE USE OF GOVERNMENT INFORMATION TO PARTICIPATE ON DEMOCRACY

COMPETENCIA INFORMACIONAL Y MEDIÁTICA CENTRADA EN LA CIUDADANÍA: USO DE INFORMACIÓN GUBERNAMENTAL COMO UNA HERRAMIENTA DE LAS DEMOCRACIAS PARTICIPATIVAS

'Rafaela Carolina da Silva, ${ }^{1}$ Selma Letícia Capinzaiki Ottonicar, ${ }^{1}$ Cristiana Aparecida Portero Yafushi

${ }^{1}$ Universidade Estadual Paulista

Correspondência

'Rafaela Carolina da Silva

Universidade Estadual Paulista

São Paulo, SP.

Email: rafacarolina@marilia.unesp.br

ORCID: http://orcid.org/0000-0001-9684-0327

Submetido em: 19-05-2017

Aceito em: 04-07-2017

Publicado: 24-07-2017

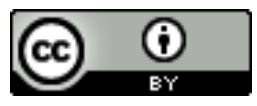

JITA: CE. Literacy 
RESUMO: As Tecnologias de Informação e Comunicação possibilitam o desenvolvimento das sociedades democráticas na medida em que permitem o acesso à informação em diferentes suportes e contextos. Desse modo, o acesso à informação governamental é apenas o primeiro passo para tornar as pessoas cidadãs, já que corrobora com o desenvolvimento da democracia ao permitir que a população saiba como interpretar e se apropriar das informações para construir conhecimento. Defende-se, assim, que o processo de uso da informação se equipara à execução da cidadania, uma vez que qualifica o indivíduo para lidar com diferentes informações transmitidas pelas mídias nas diversas esferas: social, política e profissional. A presente pesquisa tem como objetivo refletir sobre a relevância da Competência em Informação e Midiática para a construção da cidadania nas sociedades democráticas por meio do acesso online à portais governamentais brasileiros. Os procedimentos metodológicos envolvem uma pesquisa bibliográfica acerca das políticas públicas, a lei de acesso à informação do Brasil e a competência em informação. Para ser considerado competente em informação, o cidadão deve possui capacidades e habilidades para usar as informações disponibilizadas pelo governo. Não se pode ignorar o fato de que os portais online no Brasil ainda possuem entraves que, contribuem com a ineficiência da transparência política no país. Portanto, ser competente em informação é fundamental para se apropriar das informações governamentais divulgadas, tornando o indivíduo crítico na seleção, retenção e disseminação capaz de interpretar dados os dados fornecidos, bem como as ideologias que regem as fontes de informação.

PALAVRAS-CHAVE: Competência em informação. Mídia física e de comunicação. Acesso à informação. Política de informação.

ABSTRACT: The Information and Communication Technologies enable the development of democratic societies when they allow access to information in different media and contexts. Hence, the access to government information is only the first step towards making people citizens, since it corroborates to the development of the democracy by allowing the population to know how to interpret and appropriate information to build knowledge. It is argued, therefore, that the process of the use of information is equivalent to the execution of citizenship, since it qualifies the individual to deal with different information transmitted by the media in the various spheres: social, political and professional. From this perspective, the present research aims to reflect on the relevance of Information and Media Competence for the construction of citizenship in democratic societies through online access to Brazilian governmental portals. The methodological procedures involve a bibliographical research about public policies, Brazil's access to information law and information competence. To be considered competent in information, the citizen must have the skills and abilities to use the information made available by the government. One thing that can not be ignored is the fact that online portals in Brazil still have obstacles that contribute to the inefficiency of political transparency in the country. Therefore, being competent in information is fundamental to appropriate the government information disclosed, making the individual critical in the selection, retention and dissemination, as well as capable of interpreting the data provided in society and the ideologies that govern the sources of information.

KEYWORDS: Information literacy. Media education. Access to information. Development policy.

RESUMEN: Las Tecnologías de la Información y de la Comunicación permiten el desarrollo de sociedades democráticas cuando facilitan el acceso abierto a la información en diferentes medios y contextos. El acceso a la información gubernamental es el paso para la formación ciudadana; la accesibilidad a este tipo de información contribuye al avance de la democracia al permitir que la población se adueñe de la información, la interprete y genere nuevos conocimientos. Se defiende que el uso de la información es equivalente al cumplimiento de la ciudadanía, una vez que califica y habilita al individuo para manejar las diferentes informaciones trasmitidas por las diversas esferas: sociales, políticas y profesionales. La investigación pretende reflexionar sobre la relevancia de la competencia informacional y mediática para la construcción de la ciudadanía en las sociedades democráticas, a través del acceso de los portales gubernamentales brasileños. El procedimiento metodológico utilizado fue la investigación bibliográfica sobre políticas públicas, ley brasileña de acceso a la información y competencia informacional y mediática. Para ser considerado competente en información, el ciudadano debe tener capacidades, habilidades para usar las informaciones publicadas por el gobierno. No se puede ignorar que los portales brasileños aún tienen problemas que contribuyen a la ineficiencia de la transparencia política en el país. Por consiguiente, alcanzar las competencias en información es fundamental para que la población brasileña sea crítica en la selección, retención y difusión de la información. A la vez, que sea capaz de interpretar los datos proporcionados y las ideologías que rigen las fuentes de información.

\begin{tabular}{l|l|l} 
v.15 & n.3 & p.604-628
\end{tabular}
set./dez. 2017 
PALABRAS ClAVE: Alfabetización informacional. Competencia mediática. Acceso a la información. Políticas públicas de acceso a la información.

\section{INTRODUÇÃ̃}

As Tecnologias e Informação e Comunicação (TIC) possibilitaram maior transparência política nas sociedades democráticas ao possibilitar o acesso à informação em diferentes mídias e suportes. Entretanto, o acesso à informação é apenas uma etapa do processo de aplicação do conhecimento na realidade, levando em conta que, para além das TIC, existe um indivíduo capaz de interpretar e criar significados a partir da leitura e releitura que faz das informações disponíveis pela sociedade.

Nesta perspectiva, a transparência política é um dos fatores que possibilitam a execução da democracia em um país, visto que a população precisa de informação para participar do desenvolvimento de políticas públicas. A democracia é efetuada por meio dos cidadãos, governo e entidades privadas. Historicamente, a transparência pública favoreceu-se pela criação de sites de internet, objetivando demonstrar as despesas do governo.

O fato de alguns cidadãos terem acesso ao valor gasto com educação, não garante a plena participação social, uma vez que poucas pessoas sabem como utilizar as ferramentas de acesso aos segmentos ou repartições da educação. Além disso, há necessidade de melhorar a disponibilização das informações em portais estabelecidos pelo governo brasileiro. Trata-se de criar possibilidades para que os cidadãos saibam como navegar nos portais de modo a acessar as informações de maneira clara e objetiva, aumentando as possibilidades de geração de conhecimento pelo indivíduo.

Conforme afirma Norris (2001, p. 102):

Múltiplas fontes de informação deveriam estar disponíveis na sociedade civil para que os cidadãos possam entender as alternativas eleitorais, possam avaliar a eficácia da autoridade governamental, e podem prever as consequências do voto [...].

$\mathrm{Na}$ sociedade democrática, o cidadão tem o direito ao voto e com isto, escolhe os representantes da comunidade que intervém junto ao governo. As pessoas necessitam informações sobre investimentos, debates e sobre situações irregulares de cada político e projeto. Portanto, estabeleceu-se que a transparência política é meio fundamental para que o cidadão conheça o contexto dos representantes políticos e do próprio governo.

A transparência da gestão é conceituada como a atuação do órgão público, por meio da divulgação das normas e dos dados referentes as atividades para a comunidade em geral. Sendo assim, a transparência pública deve assegurar o acesso à informação de maneira global, ao invés de divulgar apenas informações convenientes (BRAGA, 2011). 
Nesse sentido, ao possibilitar que os indivíduos acessem informações de modo pleno, o Governo Brasileiro estará contribuindo para a construção da cidadania e desenvolvimento da democracia, uma vez que esses indivíduos se tornam cidadãos conscientes, competentes em informação. Os cidadãos competentes em informação aprendem a partir do uso da informação durante toda sua vida, sendo que esta competência é desenvolvida continuamente em sua capacidade intelectual e elimina barreiras que impedem o: "[...] acesso, a seleção, a gestão e avaliação da informação necessária à vida profissional, social ou pessoal" (BELLUZZO; FERES, 2015, p.8).

Esses indivíduos sabem como utilizar as ferramentas disponibilizadas nesses portais. Logo, a pessoa competente em informação deve ser capaz de se informar sobre a situação governamental maneira crítica, identificando a desinformação com mais facilidade. Ao verificar a veracidade da informação e de suas fontes, a pessoa exerce o direito ao voto de maneira consciente e eficaz com base em seus interesses. (OTTONICAR; FERES, 2014).

Neste viés, Haberle (2007) traz suas contribuições e elucida que a democracia consiste no comprometimento do Estado regido por um Governo responsável, que cria condições para os cidadãos do seu país de maneira igualitária, respeitando sua liberdade de pensamento e regendo o Direito de suas atribuições de modo pacífico, levando em consideração o bem-estar e escolha da maioria da sua população.

Silva (2008, p. 14) elucida que a cidadania envolve atributos que vai além de direitos políticos conseguidos com muitos esforços pelos cidadãos, mas também "[...] qualifica os participantes da vida do Estado, o reconhecimento do indivíduo como pessoa integrada na sociedade estatal (Art. 5, LXXVII). Significa aí, também, que o funcionamento do Estado estará submetido à vontade popular". Isto não significa que apenas os representantes de certas classes econômicas dominantes possam participar ativamente das decisões atribuídas ao Estado, mas também compreende que todos os representantes eleitos pela sociedade, em suas respectivas classes e cargos, representam esses cidadãos independente do seu fator econômico. Essa integração entre as classes e seus representantes deve ser realizada de maneira ética e com equidade para que todos os indivíduos obtenham as mesmas oportunidades, direitos e deveres, priorizando pela justiça e melhoria da nação.

Desse modo, este artigo visa refletir como a Competência em Informação (CoInfo) pode contribuir com a cidadania, assim como analisar como o uso da informação governamental de maneira inteligente influencia a participação da população no processo de democratização da sociedade. Desta forma, objetiva-se refletir de que maneira a Competência em Informação contribui no desenvolvimento da cidadania, verificando se o uso consciente da informação pública disponível promove o exercício da democracia.

Sendo assim, a justificava para o desenvolvimento deste estudo está no fato da temática ser inovadora, ao relacionar a Competência em Informação com as políticas de

\begin{tabular}{l|l|l}
$\mathrm{v} .15$ & $\mathrm{n} .3$ \\
\hline
\end{tabular}
p.604-628 set./dez. 2017 
acesso à informação para o desenvolvimento da cidadania e da democracia. É importante destacar que a maioria das pesquisas desta competência está voltada ao contexto das escolas e das bibliotecas.

\section{POLíticas públiCAS e A LEI de ACESSO À INFORMAÇÃo NO BRASIL}

A Democracia é um sistema que estimula o diálogo entre as organizações públicas, privadas e o povo. A discussão fomenta mudanças e possibilitam a evolução da sociedade. Portanto, a população tem o direito e o dever de participar politicamente em sua comunidade. De acordo com Gomes (2017, sem paginação, grifo do autor):

\footnotetext{
"É o governo do povo, para o povo, pelo povo". "Governo do povo" quer dizer governo com um sentido popular; "para o povo" significa que o objetivo é o bem do povo; "pelo povo" quer dizer realizado pelo próprio povo. Na democracia é o povo quem toma as decisões políticas importantes (direta ou indiretamente por meio de representantes eleitos).
}

No sistema de produção capitalista, é inevitável que a força maior, capaz de influenciar o governo, seja o poder econômico. As associações das empresas de diferentes ramos pressionam políticos a fim de melhorar as condições econômicas. Tal poder se confronta vezes se complementa com as organizações sociais, cujo objetivo é o de lutar pelas necessidades do povo ativamente. Ressalta-se que nem sempre os interesses dos poderes econômico e social são divergentes, tendo em vista que o sustento da população no sistema capitalista acontece por meio do emprego.

Levando em conta que no sistema democrático, a opinião do público é fundamental para o desenvolvimento de propostas governamentais, o governo deve ser capaz de fornecer à população informações que garantam a transparência de seus gastos e investimentos, permitindo que as pessoas estejam a par de onde seu dinheiro está sendo investido, o que corrobora para o exercício da cidadania. Partindo de uma perspectiva social, as políticas públicas são feitas para as pessoas (AKUTSU; PINHO, 2002).

A sociedade da informação possui o direito à informação de um modo amplo e compartilhado, tal direito ocorre por meio do compartilhamento de informações. Não exercer o direito de informação significa não contribuir com a democracia e fortalecer tanto a exclusão digital como a social.

Sendo assim, o direito à informação é possibilita atuação democrática por parte do cidadão, uma vez que conhece as ações governamentais (CARVALHO, 2010) e uma comparação dos dados fornecidos. Os indivíduos que não têm acesso às condições básicas de direito, como moradia, saúde e educação, raramente exercerão seu direito à informação, acabando por consumir os produtos da indústria cultural sem reflexão crítica. Entretanto o 
acesso sozinho, não garante o poder do cidadão, portanto a pessoa deve ser capaz de interpretar os dados, compará-los, construir conhecimento e tomar uma decisão.

Segundo Carvalho (2010), ainda que exista uma constituição estabelecida, o direito à informação não é exercido, porque o cidadão não possui conhecimento sobre o assunto. Assim, sem perceberem, os indivíduos acabam por se tornar instrumentos passivos do sistema. Diferentes nações têm disponibilizado informações por meio de portais online, já que perceberam a importância da transparência para a sociedade, porém os tipos de informações fornecidas nem sempre atendem às necessidades do cidadão.

É nesse contexto que há uma discussão a respeito da transparência governamental, que recebeu maior importância devido ao desenvolvimento das indústrias de TIC. Além disso, percebe-se que em vários países do mundo há criação de ferramentas que permitem a comunicação das informações do Estado. Nessa perspectiva, quando bem utilizadas, as ferramentas de divulgação governamental possibilitam que qualquer cidadão tenha acesso utilizando a internet, vista como um dos instrumentos mais eficazes na composição de uma democracia eficiente (AKUTSU; PINHO, 2002).

No dia 18 de novembro de 2011, foi aprovada a lei de Acesso à Informação, colocando o Brasil como um dos pioneiros a adotar tal constituição. Tal ação significa que o país inclui mais um item democrático em seu sistema governamental, permitindo maior participação dos cidadãos e favorecendo os instrumentos de investigação da gestão pública (CONTROLADORIA GERAL DA UNIÃO, 2011).

A informação produzida pelo Estado é considerada como pública, entretanto, existem algumas situações específicas que são restringidas. $\mathrm{Na}$ execução da democracia é fundamental que a sociedade tenha acesso a esses documentos, arquivos e estatísticas (CONTROLADORIA GERAL DA UNIÃO, 2011).

As informações passíveis de serem restringidas são denominadas como "informações sigilosas", são aquelas que podem prejudicar a sociedade de alguma maneira. Não obstante, são informações temporárias podendo ser publicadas futuramente. Na maioria das vezes, as informações secretas dizem respeito à segurança nacional ou às informações pessoais dos cidadãos (OTTONICAR; FERES, 2014).

No capítulo I da constituição, dos Direitos e Deveres Individuais e Coletivos, no inciso XXXIII do artigo 5, foi redigido que:

[...] todos tem direito a receber dos órgãos públicos informações de seu interesse particular, ou de interesse coletivo ou geral, que serão prestadas no prazo da lei, sob pena de responsabilidade, ressalvadas aquelas cujo sigilo seja imprescindível à segurança da sociedade e do Estado". (CONTROLADORIA GERAL DA UNIÃO, 2011, p. 10). 
Uma vez que o indivíduo possua internet, é possível acessar as informações por meio de diferentes portais criados pelo governo no nível federal, estadual e municipal. A informação é, portanto, um dos elementos mais fortes no combate à corrupção de qualquer nação.

Além da internet, o governo brasileiro se utiliza da televisão, como o canal TV NBR, que divulga as ações do Poder Executivo, do presidente atual e das políticas públicas. Existem também programas de rádio, como a voz do Brasil que trata das informações do Governo Federal, entre outras plataformas, que seguem o mesmo objetivo: suprir as necessidades informacionais das pessoas (OTTONICAR; FERES, 2014).

$\mathrm{Na}$ vida das pessoas existem diferentes opções a serem escolhidas, que estão relacionadas com as informações tanto na aquisição de um produto quanto na decisão de voto em um candidato político. No sistema democrático, o processo eleitoral é imprescindível, cabendo ao governo possibilitar que o indivíduo vote bem informado (ANDI, 2011).

O voto consciente está associado com o maior volume possível de informações. Consequentemente, no Brasil, criou-se o Horário Eleitoral Gratuito, que incentiva os candidatos apresentar suas ideias ao público pelas empresas de rádio fusão (ANDI, 2011).

Segundo Carvalho (2010, p. 72): “[...] devemos cobrar do Estado garantia e manutenção dos direitos do cidadão. A política nacional de inclusão digital deve, por conseguinte, privilegiar espaços para que esse direito possa ser exercido". O Portal da Transparência, além de divulgar informações, fornece opções de uso dos dados governamentais, estimulando os usuários a disseminá-los por meio das redes sociais.

O acesso é o primeiro passo para que o indivíduo exerça sua cidadania, pois fornece um arcabouço informacional variado que pode dificultar a compreensão. Desse modo, não basta apenas buscar informação nas plataformas online ou nas mídias porque o indivíduo precisa ser capaz de criticar a informação coletada, fazendo conexões com outros dados obtidos pela televisão, rádio, internet, entre outros meios. Tais críticas fazem do processo de aprendizagem e consequentemente, a pessoa constrói conhecimento sobre fatos durante toda a vida. A construção do conhecimento por meio da aprendizagem reflexiva das informações e análises de suas fontes é um dos principais objetivos da competência em informação, explicada pela próxima seção.

\section{COMPETÊNCIA EM INFORMAÇÃ̃ E MIDIÁtICA NO CONTEXTO DA CIDADANIA}

O exercício da cidadania tem papel fundamental na democracia, pois permite aos indivíduos enquanto cidadãos demonstrarem seus interesses e suas contribuições ao país, na

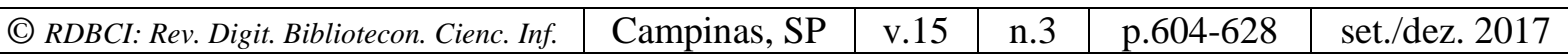


medida que agem com responsabilidade, ética, sinergia, para a construção de um país cada vez mais promissor, integrador e justo, proporcionando a sua participação enquanto eleitor e cidadão. Cabe aos indivíduos contribuir com as decisões, regulamentações e leis sancionadas pelo Governo cujo objetivo pode ser político, econômico, social e cultural.

Nesse âmbito, Camargo (2017, sem paginação, grifo nosso) corrobora com a definição de cidadania ao enfatizar:

\begin{abstract}
O termo cidadania tem origem etimológica no latim civitas, que significa "cidade". Estabelece um estatuto de pertencimento de um indivíduo a uma comunidade politicamente articulada - um país - e que lhe atribui um conjunto de direitos e obrigações, sob vigência de uma constituição. Ao contrário dos direitos humanos que tendem à universalidade dos direitos do ser humano na sua dignidade -, a cidadania moderna, embora influenciada por aquelas concepções mais antigas, possui um caráter próprio e possui duas categorias: formal e substantiva (CAMARGO, 2017, sem paginação, grifo nosso).
\end{abstract}

Ser cidadão é ter comprometimento com a comunidade e exercer os direitos e obrigações que regem as pessoas. É também compreender o impacto da vida política no dia a dia e, por isso, está diretamente relacionado com o poder de voto. Para o cidadão, o voto não é visto como uma obrigação, mas um direito adquirido que possibilita a participação democrática.

A cidadania é um ganho fundamental para a sociedade e está em construção de maneira cíclica. Manifesta-se por meio das pessoas, que sempre buscam mais direitos, liberdades, garantias individuais e coletivas. São indivíduos que não se conformam com a dominação vigente do Estado ou de outras instituições (CAMARGO, 2017).

A Austrália e os Estados Unidos são países que possuem políticas públicas voltadas à competência em informação de maneira consolidada, se comparada à outras nações. No Brasil, existem mais esforços realizados por pesquisadores do que iniciativas governamentais, entretanto, a organização de congressos que discutem o tema contribui com a sua popularização entre a sociedade (OTTONICAR; FERES, 2014).

Os esforços realizados no Brasil para disseminação da competência em informação estão direcionados a educação, como a criação do Programa de Incentivo à Biblioteca, a criação da Federação Brasileira de Associações de Bibliotecários (FEBAB), a criação do Grupo Assessor para a Competência em Informação, formado pela Secretaria da Cultura do Estado de São Paulo, juntamente com a FEBAB, entre outras iniciativas (OTTONICAR; FERES, 2014).

De acordo com Belluzzo e Feres (2015, p. 8) a Competência em Informação é conceituada como: 
[...] competência funcional na sociedade contemporânea torna-se, pois, crucial para a realização de cada cidadão e para sua plena integração social. $O$ seu desenvolvimento capacita os indivíduos para o acesso, a seleção, a gestão e avaliação da informação necessária à vida profissional, social ou pessoal.

A competência em informação é relevante para a análise e interpretação de qualquer informação, inclusive aquelas de origem duvidosa. As fontes de informação são analisadas a partir de suas ideologias, assim o indivíduo compreende que um texto não é neutro, mas carrega opiniões próprias do autor. Não apenas textos, mas também cabe ao indivíduo compreender as mensagens emitidas pelos demais veículos de comunicação emitidos por diversas mídias.

Assim, o indivíduo necessita ser competente no uso das mídias, competência conhecida como midiática. Nesse sentido a competência midiática, juntamente com a competência em informação, contribui para que o indivíduo saiba lidar com as demandas do século XXI e utilize as potencialidades de ambas competências para geração de oportunidade de crescimento, desenvolvimento e criação de novos conhecimentos.

Desta forma, a competência midiática está baseada na:

“[...] compreensão e o uso das mídias de massa de maneira incisiva ou não, incluindo um entendimento bem informado e crítico das mídias, das técnicas que elas empregam e dos seus efeitos. Incluindo a capacidade de ler, analisar, avaliar e produzir a comunicação em uma série de formatos de mídias. (DE FARIAS, 2017, p. 163).

As informações governamentais são disseminadas por meio da mídia, ferramentas de difusão da informação para as pessoas. $\mathrm{O}$ cidadão consciente sabe como usar tais ferramentas e conhece a cadeia produtiva, além disso, o próprio cidadão pode compartilhar suas ideias e pensamentos por meio de sites, blogs, redes sociais e outras ferramentas criadas para dar visibilidade às pessoas na rede.

As habilidades e capacidades relacionadas ao indivíduo competente em informação e competente midiático possibilitaram o desenvolvimento de padrões e indicadores que norteiam as pesquisas nesta área. Os padrões foram criados internacionalmente e são flexíveis, pois se adaptam aos contextos de cada país.

Neste aspecto, Belluzzo (2013), aborda que a consolidação da competência em informação e midiática necessita de sustentação, visando atender três requisitos fundamentais: cidadania, crescimento econômico e empregabilidade. A cidadania abrange o uso crítico tanto de dados como de informação; o crescimento econômico abrange o uso de forma criativa e intensa do conhecimento combinado à eficiência dos serviços de informação; e por fim a empregabilidade que abrange o desenvolvimento contínuo dos indivíduos, que utilizam-se de estratégias necessárias para alcançar o sucesso econômico. Neste viés, as 
pessoas necessitam de um olhar mais criterioso a respeito da compreensão sobre o desenvolvimento da competência em informação e midiática em âmbito nacional.

Segundo Casarin (2017, p. 305): a competência midiática "[...] abrange uma série de competências relacionadas à comunicação, incluindo a capacidade de acessar, analisar, avaliar e comunicar informações de maneiras variadas". Nesse sentido, a competência midiática possui elementos em seus conceitos que são semelhantes as definições de competência e informação, porém envolve tanto o uso das tecnologias quanto das mídias. Sendo assim, ambas competências se complementam e são fundamentais para o exercício da cidadania.

Essas competências são necessárias à sociedade, pois as tecnologias transformaram os processos e comportamentos comunicacionais dos indivíduos (UNESCO, 2017). Nesse cenário a alfabetização midiática ${ }^{1}$ tem como missão: “[...] empoderar cidadãos provendo-lhes competências (conhecimento, habilidades e atitude) necessárias para engajar a mídia tradicional com as novas tecnologias" (UNESCO, 2017, sem paginação). Desse modo, a UNESCO (2017) espera que os indivíduos sejam capazes de entender o papel das mídias na democracia, avaliar a mensagem emitida pela mídia de maneira crítica, compreender a condição utilizada pela mídia para que possa realizar suas funções, participar de modo democrático por meio da mídia e inspecionar as habilidades como a de uso das TIC importantes para a produção de conteúdo pelos usuários.

No Brasil, a pesquisadora Belluzzo (2007) traduziu e adaptou os padrões e indicadores de competência em informação e competência midiática, que se adaptam ao contexto brasileiro. Os padrões são divididos em cinco categorias, cada padrão possui indicadores que por sua vez, apresentam os resultados desejáveis. Esses padrões e indicadores podem ser adaptados no contexto do exercício da cidadania, a fim de guiar os indivíduos no processo de busca da informação governamental.

O primeiro padrão aponta que a pessoa competente em informação e em mídia determina a natureza e a extensão da necessidade de informação, ou seja, em termo de cidadania, o indivíduo percebe de qual tipo de informação precisa para construir conhecimento sobre um projeto, programa ou lei proposta pelo Governo. Os indicadores demonstram que o cidadão define e reconhece a necessidade de informação, identifica uma variedade de tipos e formatos de fontes de informação potenciais, e considera os custos e benefícios da aquisição da informação necessária e seu impacto para a sociedade.

O segundo padrão aponta que o cidadão competente em informação e em mídia acessa a informação necessária com efetividade, pois conhece os portais governamentais e as

\footnotetext{
${ }^{1}$ A alfabetização midiática é entendida pela UNESCO (2017, sem paginação) como a educação voltada as mídias e as tecnologias.
} 
diferentes mídias onde a informação pública é disseminada como os canais de televisão, programas de rádio, sites da internet, redes sociais, entre outros. Os indicadores de desempenho do segundo padrão apontam que o indivíduo seleciona os métodos mais apropriados de busca e/ou sistemas de recuperação para acessar a informação necessária, constrói e implementa estratégias de busca delineadas com efetividade, busca a informação via eletrônica ou com pessoas utilizando uma variedade de métodos, retrabalha e melhora a estratégia de busca quando necessária, e extraí, registra e gerencia a informação e suas fontes.

Já o terceiro padrão aponta que a pessoa competente em informação e em mídia avalia criticamente as informações e suas fontes, assim o cidadão precisa compreender as intenções por traz de uma informação e do meio midiático a que circula. As fontes de informação como os canais, os veículos de comunicação são geridos por pessoas e sabe-se que os indivíduos são movidos por crenças, intenções e ideologias. Os resultados de desempenho do terceiro padrão apontam que o cidadão demonstra conhecimento da maior parte das ideias da informação obtida, articula e aplica critérios de avaliação para a informação e suas fontes, e compara novo conhecimento com o conhecimento anterior pra determinar o valor agregado, contradições ou outra característica da informação.

O padrão 4 aponta que a pessoa competente em informação, individualmente ou como membro de um grupo, usa a informação com efetividade para alcançar um objetivo/obter um resultado. Nessa perspectiva, o cidadão usa a informação para exercer cidadania por meio das escolhas dos políticos no momento do voto, opiniões a respeito de políticas públicas estabelecidas pelos governos federal, estadual e municipal, busca informação sobre as propostas de leis em tramitação na câmara e no plenário. Os indicadores de desempenho demonstram que o indivíduo é capaz de sintetizar a informação para desenvolver ou completar um projeto, no caso do cidadão a síntese é importante no processo de compreensão do programa ou lei expostos para o público, outro indicador de desempenho comunica os resultados projeto, programa ou lei governamental com efetividade. É importante lembrar que na sociedade da informação o cidadão consome e produz informação.

O padrão 5 aponta que a pessoa competente em informação e em mídia compreende as questões econômicas, legais e sociais da ambiência do uso da informação e acessa e usa a informação ética e legalmente. Portanto, o cidadão para tomada de decisão precisa ter entendimento macro sobre a situação governamental e a posição do país no contexto mundial. Os indicadores de desempenho indicam que demonstra a compreensão sobre as questões éticas, legais e socioeconômicas que envolvem a informação, a comunicação e a tecnologia, também cumpre as leis, regulamentos, políticas institucionais e normas relacionadas ao acesso e uso às fontes de informação, e indica as fontes de informação nas comunicações do produto, resultados projetos e programas governamentais.

A divulgação de informação é facilmente percebida nos períodos de disputas partidárias nas eleições de um país, às quais permitem diferentes tipos de informações que

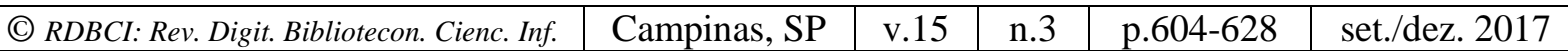


favorecem um candidato e atrapalha outro (OTTONICAR; FERES, 2014). Assim, o indivíduo necessita ser competente e considerar várias fontes de informação sobre o político e suas intenções para o país e principalmente verificar a qual ideologia o partido político pertence. A Controladoria Geral da União (2011, p.8) considera que o cidadão bem informado:

[...] tem melhores condições de conhecer e acessar outros direitos essenciais, como saúde, educação e benefícios sociais. Por este e por outros motivos, o acesso à informação pública tem sido, cada vez mais, reconhecido como um direito em várias partes do mundo (CONTROLADORIA GERAL DA UNIÃO, 2011, p. 8).

A fim de estimular a competência em informação nos cidadãos brasileiros, o governo recentemente tem se utilizado da internet para realizar transparência política, informando à população sobre os gastos e investimentos governamentais. Os sites públicos são conhecidos como portaltransparencia.gov.br, cgu.gov.br, e acessoainformaçao.gov.br, planalto.gov.br (OTTONICAR; FERES, 2014).

\section{MÉTODO}

O presente trabalho se constitui de um estudo bibliográfico que, segundo Gil (2008, p. 50): "é desenvolvido a partir de material já elaborado, constituído de livros e artigos científicos". Foi desenvolvido por meio da coleta de informações em diferentes fontes consideradas confiáveis, como sites, artigos de revista, capítulo de livro e livros da área da Ciência da Informação, Competência em Informação e Políticas Públicas.

A pesquisa bibliográfica para Boccato (2006) busca solucionar um problema com base no referencial teórico publicado e disponibilizado pelos diferentes autores reconhecidos pelas suas contribuições científicas com o intuito de agregar na construção de conhecimento dos pesquisadores, auxiliando dessa forma, o pesquisador na concretização de seu planejamento. Além disso, tal tipo de pesquisa relaciona todo o aporte teórico absorvido com a aplicabilidade pratica, compartilhando suas ideologias por meio da comunicação e divulgação da sua pesquisa, consolidando temas e ideais que serão relevantes tanto para a área de pesquisa quanto ao estímulo a novas reflexões para futuras pesquisas.

Ao refletir sobre a hipótese levantada, o pesquisador busca respondê-la com base no material de autores reconhecidos pela área, mediante as contribuições científicas consolidadas para fomentar a construção de conhecimento. Para tanto, desenvolve um planejamento criterioso e sistêmico que engloba todo o processo da sua pesquisa e perpassa pelos diversos elementos que compreendem esse universo como a definição do tema, a construção racional e objetiva do corpus da pesquisa e a escolha da forma de comunicação e divulgação de seu trabalho. 
Este tipo de pesquisa possibilita o desenvolvimento de novos conceitos, como o da Competência em Informação em âmbito político, cujo objetivo é contribuir com o desenvolvimento da cidadania na sociedade. Nesse trabalho, a literatura revisada fez uma interlocução entre os temas da competência em informação, da democracia, cidadania e da lei de acesso à informação pública. Tais temas são fundamentais para o uso da informação inteligente com base na transparência política dos órgãos competentes.

\section{DISCUSSÕES}

Os agentes sociais exercem sua cidadania nas diferentes esferas do país, a educação porque valoriza a informação e o conhecimento para a compreensão do país e suas dificuldades, a econômica, pois gera renda para a nação e estimula o emprego da população, e também na esfera cultural/social, já que cria condições para melhorar a qualidade de vida dos indivíduos por meio dos atributos da paz, preservação do meio ambiente, do voto e da memória de um povo.

A competência em informação se faz necessária nas três esferas a fim de que o exercício da cidadania em cada uma delas ocorra de maneira inteligente. Para tanto os padrões e indicadores de competência em informação e competência midiática servem de norteadores para o cidadão saber como acessar, avaliar e usar a informação com base em suas habilidades, capacidades e experiências. Esses padrões norteiam as ações dos cidadãos competentes em informação e em mídia, conforme exposto no quadro 1.

Quadro 1. Inter-relação entre as três principais esferas sociais, os padrões e indicadores de competência em informação e midiática e as ações do cidadão.

\begin{tabular}{|c|c|c|}
\hline $\begin{array}{l}\text { Três principais } \\
\text { esferas da cidadania }\end{array}$ & $\begin{array}{l}\text { Padrões e Indicadores de Competência em informação e } \\
\text { Competência Midiática } \\
\text { (BELLUZZO, 2007) }\end{array}$ & $\begin{array}{l}\text { Principais ações do } \\
\text { cidadão competente em } \\
\text { informação e midiático }\end{array}$ \\
\hline Educação & $\begin{array}{l}\text { PADRÃO 1 - A pessoa competente em informação } \\
\text { determina a natureza e a extensão da necessidade de } \\
\text { informação } \\
\text { Indicador de desempenho: } 1.1 \text { Define e reconhece a } \\
\text { necessidade de informação; } \\
\text { Resultados desejáveis: } 1.1 .3 \text { Usa fontes de informação gerais } \\
\text { ou específicas para aumentar o seu conhecimento sobre o } \\
\text { tópico; } \\
\text { Indicador de desempenho: } 1.3 \text { Considera os custos e benefícios } \\
\text { da aquisição da informação necessária; } \\
\text { Resultados desejáveis: } 1.3 .1 \text { Determina a disponibilidade da } \\
\text { informação necessária e toma decisões sobre as estratégias de } \\
\text { pesquisa da informação e o uso de serviços de informação e } \\
\text { qual a mídia adequada; } \\
\text { PADR ÃO } 2 \text { - A pessoa competente em informação acessa a } \\
\text { informação necessária com efetividade }\end{array}$ & $\begin{array}{l}\text { Avaliação crítica do } \\
\text { conteúdo midiático, } \\
\text { envolve senso crítico } \\
\text { quanto as funções da mídia } \\
\text { como: pensamento crítico, } \\
\text { construção e desconstrução } \\
\text { de conhecimento, criação } \\
\text { de novos conhecimentos e } \\
\text { aprendizado ao longo da } \\
\text { vida; } \\
\text { Garantia do acesso e uso da } \\
\text { informação de forma } \\
\text { inteligente para a geração } \\
\text { de conhecimento às } \\
\text { comunidades assistidas e } \\
\text { populações vulneráveis. }\end{array}$ \\
\hline
\end{tabular}




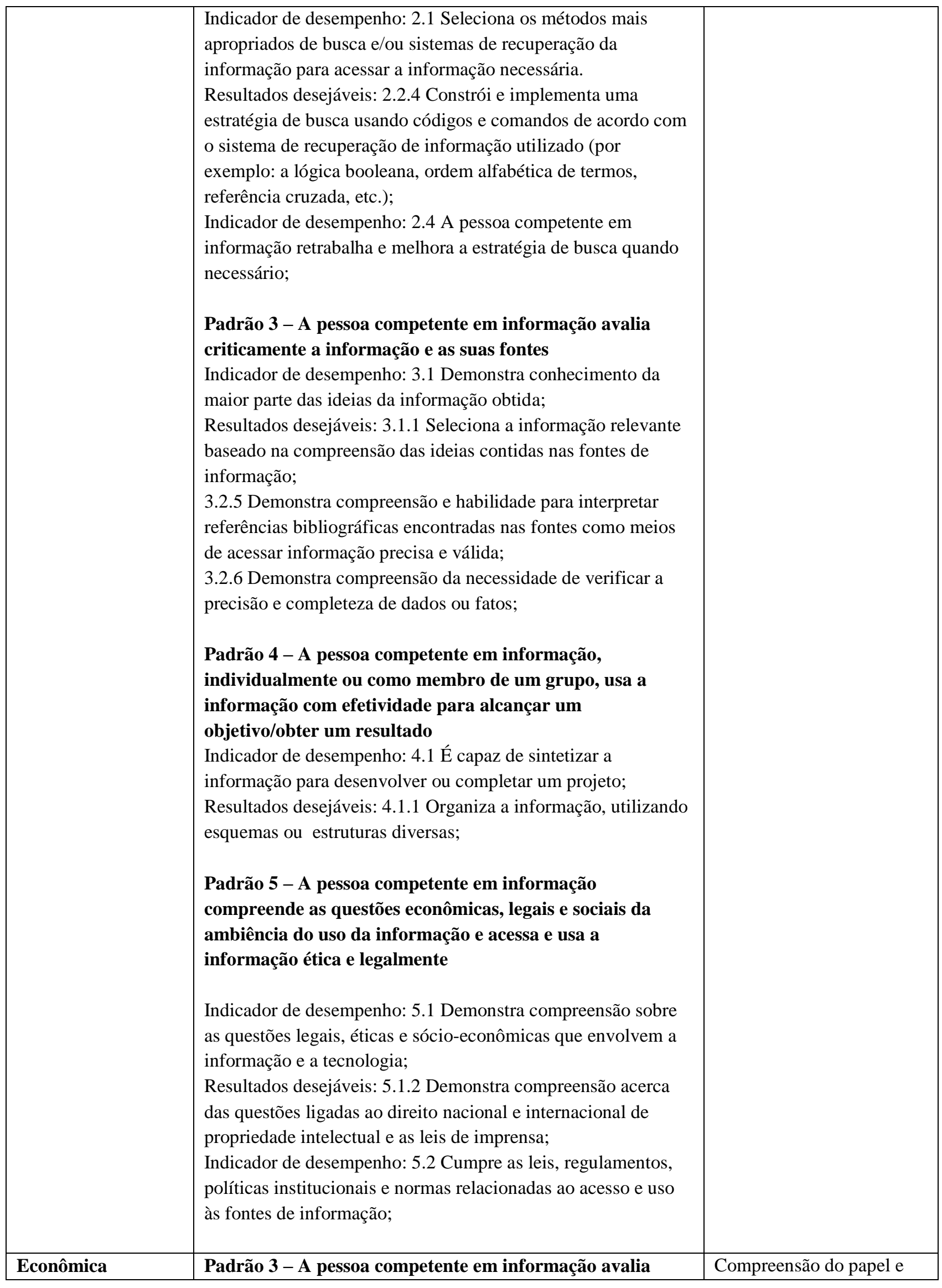

\begin{tabular}{|c|c|c|c|c|c|}
\hline CI: Rev. Di & Campinas, SP & v.15 & n. 3 & p. 604-628 & set/dez, 2017 \\
\hline
\end{tabular}




\begin{tabular}{|c|c|c|}
\hline & $\begin{array}{l}\text { criticamente a informação e as suas fontes } \\
\text { Indicador de desempenho: } 3.1 \text { Demonstra conhecimento da } \\
\text { maior parte das ideias da informação obtida; } \\
\text { Resultados desejáveis: } 3.2 .6 \text { Demonstra compreensão da } \\
\text { necessidade de verificar a precisão e completeza de dados ou } \\
\text { fatos; } \\
\text { Indicador de desempenho: } 3.3 \text { Compara o novo conhecimento } \\
\text { com o conhecimento anterior para determinar o valor } \\
\text { agregado, contradições ou outra característica da informação; } \\
\text { Resultados desejáveis: } 3.3 .4 \text { Seleciona a informação que traz } \\
\text { evidências para o problema /tópico de pesquisa ou outra } \\
\text { informação necessária; } \\
\text { Padrão 5 - A pessoa competente em informação } \\
\text { compreende as questões econômicas, legais e sociais da } \\
\text { ambiência do uso da informação e acessa e usa a } \\
\text { informação ética e legalmente; } \\
\text { Indicador de desempenho: } 5.1 \text { Demonstra compreensão sobre } \\
\text { as questões legais, éticas e sócio-econômicas que envolvem a } \\
\text { informação e a tecnologia; } \\
\text { Resultados desejáveis: } 5.1 .2 \text { Demonstra compreensão acerca } \\
\text { das questões ligadas ao direito nacional e internacional de } \\
\text { propriedade intelectual e as leis de imprensa; } \\
\text { Indicador de desempenho: } 5.2 \text { Cumpre as leis, regulamentos, } \\
\text { políticas institucionais e normas relacionadas ao acesso e uso } \\
\text { às fontes de informação; }\end{array}$ & $\begin{array}{l}\text { das funções das mídias na } \\
\text { sociedade democrática - } \\
\text { utilização das } \\
\text { competências profissionais } \\
\text { desenvolvidas pelos } \\
\text { indivíduos necessárias para } \\
\text { questionamentos, análises } \\
\text { assertivas, transmissão de } \\
\text { conhecimento e produção } \\
\text { de informações pontuais e } \\
\text { significativas. } \\
\text { Compreensão das } \\
\text { condições sob as quais as } \\
\text { mídias podem cumprir suas } \\
\text { funções - instrumento de } \\
\text { garantia de } \\
\text { compartilhamento de } \\
\text { informações necessárias e } \\
\text { transferíveis geradoras de } \\
\text { mudanças da sociedade. } \\
\text { Atualização de princípios e } \\
\text { práticas de condutas de } \\
\text { gestão da informação } \\
\text { àqueles que atuam como } \\
\text { mediadores e } \\
\text { multiplicadores no } \\
\text { desenvolvimento da } \\
\text { Competência em } \\
\text { Informação, contribuindo } \\
\text { com a inovação e o } \\
\text { desenvolvimento social. }\end{array}$ \\
\hline Social / Cultural & $\begin{array}{l}\text { PADRÃO 1 - A pessoa competente em informação } \\
\text { determina a natureza e a extensão da necessidade de } \\
\text { informação } \\
\text { Indicador de desempenho: } 1.1 \text { Define e reconhece a } \\
\text { necessidade de informação; } \\
\text { Resultados desejáveis: } 1.1 .2 \text { Formula questões apropriadas } \\
\text { baseado na informação necessária ou tópico de pesquisa; } \\
\text { 1.1.3 Usa fontes de informação gerais ou específicas para } \\
\text { aumentar o seu conhecimento sobre o tópico; } \\
\text { 1.2.1 Identifica o valor e as diferenças de potencialidades de } \\
\text { fontes em uma variedade de formatos (documentos impressos e } \\
\text { eletrônicos, pessoas, instituições, etc.); } \\
\text { 1.3.1 Determina a disponibilidade da informação necessária e } \\
\text { toma decisões sobre as estratégias de pesquisa da informação e } \\
\text { o uso de servicos de informação (por exemplo: intercâmbio, }\end{array}$ & $\begin{array}{l}\text { Compromisso junto as } \\
\text { mídias para autoexpressão } \\
\text { e a participação } \\
\text { democrática - contexto } \\
\text { estimulador de } \\
\text { aprendizado, compreensão } \\
\text { e interação entre os } \\
\text { acontecimentos e fatos } \\
\text { vivenciados no contexto } \\
\text { local, regional e mundial. } \\
\text { Reforça o pensamento } \\
\text { racional, reflexivo e crítico } \\
\text { mediante o acesso efetivo } \\
\text { de informações } \\
\text { disponibilizadas pelas TIC }\end{array}$ \\
\hline
\end{tabular}

\begin{tabular}{|c|c|c|c|c|c|}
\hline CI: Rev. Digi & Campinas, SP & v.15 & n.3 & p.604-628 & \\
\hline
\end{tabular}




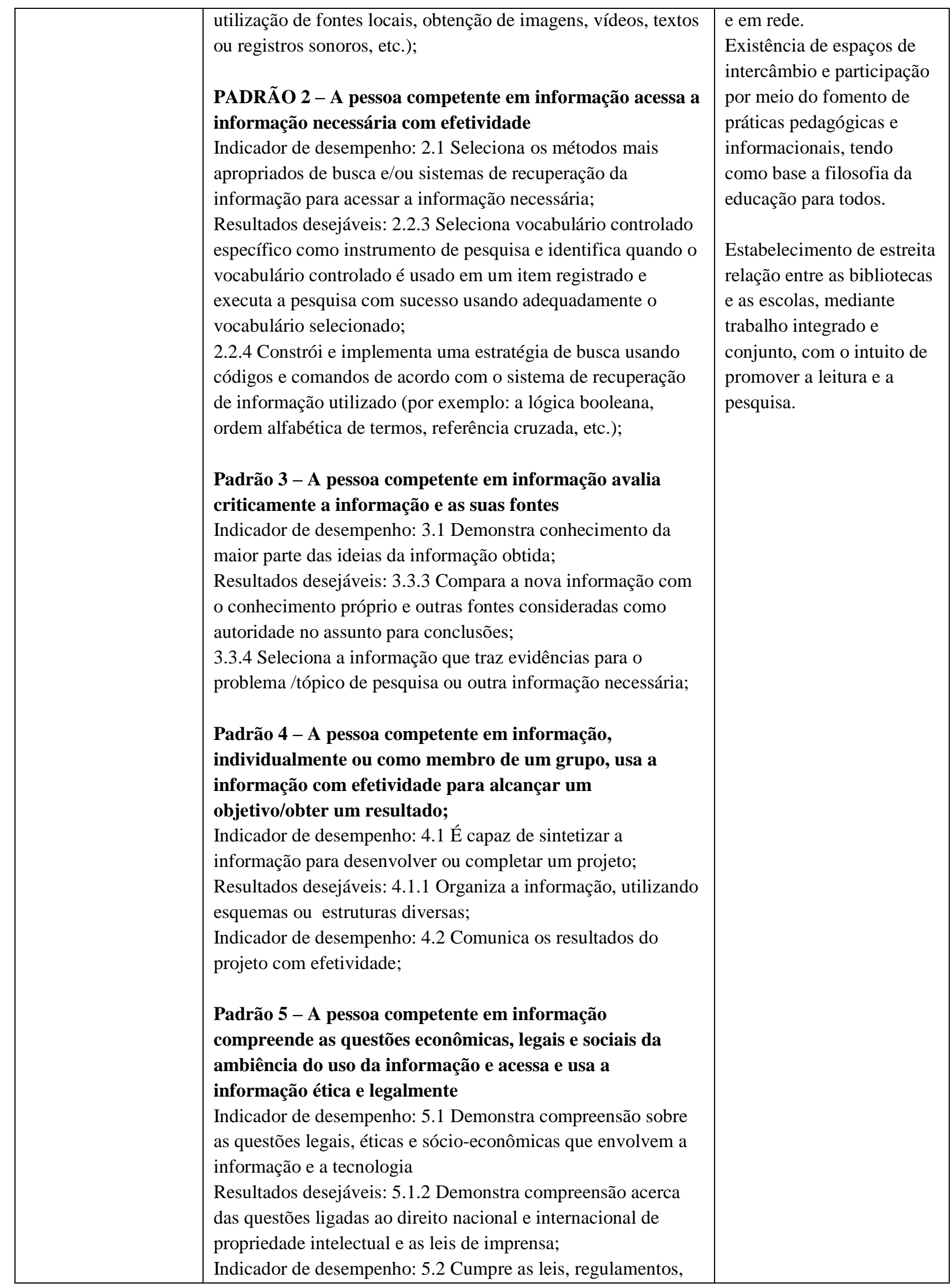


políticas institucionais e normas relacionadas ao acesso e uso

às fontes de informação;

Fonte: Adaptado de Belluzzo (2007, p. 95-103; 2013, p. 77, 164) e Wilson et al (2013, p. 18)

A esfera educacional é considerada a mais importante para o desenvolvimento da cidadania, pois é base da construção do conhecimento ao longo da vida. Os indivíduos necessitam saber ler escrever, interpretar, sintetizar, compartilhar as informações bem como manusear as tecnologias. A educação contribui para a construção de todas essas habilidades e capacidades, desde a infância do indivíduo.

O indivíduo necessita avaliar criticamente o conteúdo midiático e tal prática envolve senso crítico quanto às funções da mídia. $O$ pensamento crítico, a construção e desconstrução de conhecimento, a criação de novos conhecimentos e o aprendizado ao longo da vida (WILSON et al, 2013) são elementos estimulados pela educação, não obstante deve garantir o acesso e uso da informação de forma inteligente para a geração de conhecimento às comunidades assistidas e populações vulneráveis.

Desse modo, consideram-se todos os padrões e indicadores de competência em informação e midiática nessa fase uma vez que para acessar a informação a pessoa precisa ter determinado a natureza e a extensão da necessidade da informação (padrão 1), utilizando de fontes gerais e específicas para aumentar o seu conhecimento sobre o tópico (indicador de desempenho 1.3) e com isso, determinar a disponibilidade da informação necessária e tomar decisões sobre as estratégias de pesquisa da informação e o uso de serviços de informação e qual a mídia adequada (resultado desejável 1.3.1).

Além disso, a educação possibilita o acesso a informação necessária com efetividade (padrão 2) tendo em vista que o indivíduo deve selecionar os métodos mais apropriados de busca e/ou sistemas de recuperação da informação para acessar a informação necessária (indicador de desempenho 2.1) e com isso passe a construir e implementar estratégia de busca usando códigos e comandos de acordo com o sistema de recuperação de informação utilizado (resultado desejável 2.2.4). Não obstante, o cidadão competente em informação sabe como retrabalhar e melhorar a estratégia de busca quando necessário.

Além de diagnosticar a necessidade e acessar a informação, a pessoa precisa avaliar criticamente a informação e as suas fontes (padrão 3) ao demonstrar conhecimento da maior parte das ideias da informação obtida (indicador de desempenho 3.1), e assim selecionar a informação relevante baseada na compreensão das ideias contidas nas fontes de informação (resultado desejável 3.1.1), demonstrar a compreensão e habilidade para interpretar referências bibliográficas encontradas nas fontes como meios de acessar informação precisa e válida (resultado desejável 3.2.5) e compreender a necessidade de verificar a precisão e completeza de dados ou fatos (resultado desejável 3.2.6).

A educação realiza todas suas atividades voltadas ao indivíduo a fim de que individualmente ou como membro de um grupo, use a informação com efetividade para 
alcançar um objetivo/obter um resultado (padrão 2) e seja capaz de sintetizar a informação para desenvolver ou completar um projeto (indicador de desempenho 4.1) e como resultado saiba organizar a informação, utilizando esquemas ou estruturas diversas (resultado desejável 4.1.1). O uso de tal padrão, indicador de desempenho e resultado desejável norteia a construção do conhecimento a partir de novas ideias e experiências.

Portanto, a educação tem como objetivo final formar cidadãos conscientes que sejam capazes de compreender as questões econômicas, legais e sociais da ambiência do uso da informação e acessa e usa a informação ética e legalmente (padrão 5) e demonstre entender as questões legais, éticas e socioeconômicas que envolvem a informação e a tecnologia (indicador de desempenho 5.1) demonstre a compreensão acerca das questões ligadas ao direito nacional e internacional de propriedade intelectual e as leis de imprensa (resultado desejável 5.1.2) e, também, cumpra as leis, regulamentos, políticas institucionais e normas relacionadas ao acesso e uso às fontes de informação (indicador de desempenho 5.2).

Já na esfera econômica o cidadão necessita compreender o papel e as funções das mídias na sociedade democrática, por meio da utilização das competências profissionais desenvolvidas pelos indivíduos necessárias para questionamentos, análises assertivas, transmissão de conhecimento e produção de informações pontuais e significativas. Tais ações são norteadas pelo padrão 3 no qual a pessoa competente em informação avalia criticamente a informação e as suas fontes a fim de que compreenda o papel das mídias na sociedades e principalmente a ideologia por trás das fontes, assim o indivíduo deve demonstrar conhecimento da maior parte das ideias da informação obtida (indicador de desempenho 3.1), demonstrar a compreensão da necessidade de verificar a precisão e completeza de dados ou fatos (resultados desejáveis 3.2.6), comparar o novo conhecimento com o conhecimento anterior para determinar o valor agregado, contradições ou outra característica da informação (indicador de desempenho 3.3) selecionar a informação que traz evidências para o problema /tópico de pesquisa ou outra informação necessária (resultados desejáveis 3.3.4).

Ainda no contexto econômico, o cidadão tem compreensão das condições sob as quais as mídias podem cumprir suas funções, consideradas como instrumento de garantia de compartilhamento de informações necessárias e transferíveis geradoras de mudanças da sociedade. Não obstante, atualizar princípios e práticas de condutas de gestão da informação àqueles que atuam como mediadores e multiplicadores no desenvolvimento da competência em informação, contribuindo com a inovação e o desenvolvimento social.

Tais ações são orientadas pelo padrão 5 ao explicar que a pessoa competente em informação compreende as questões econômicas, legais e sociais da ambiência do uso da informação e acessa e usa a informação ética e legalmente, assim, mais detalhadamente necessita demonstrar a compreensão sobre as questões legais, éticas e socioeconômicas que envolvem a informação e a tecnologia (indicador de desempenho 5.1), demonstra compreensão acerca das questões ligadas ao direito nacional e internacional de propriedade 
intelectual e as leis de imprensa (Resultados desejáveis: 5.1.2) e principalmente cumprir as leis, regulamentos, políticas institucionais e normas relacionadas ao acesso e uso às fontes de informação (indicador de desempenho 5.2). Ressalta-se que o cidadão competente em informação e competente midiático também necessita conhecer as políticas públicas de acesso a informação voltada à transparência política, condição indispensável para o exercício na sociedade democrática.

Por fim, nas esferas social e cultural, o cidadão deve ter compromisso junto as mídias para auto expressão e a participação democrática num contexto estimulador de aprendizado, compreensão e interação entre os acontecimentos e fatos vivenciados no contexto local, regional e mundial. Desse modo, o âmbito cultural e social conta as diretrizes de todos os padrões de competência em informação e midiática cujo objetivo final é indicado pelo padrão 5, pois o cidadão competente em informação e em mídia compreende as questões econômicas, legais e sociais da ambiência do uso da informação e acessa e usa a informação ética e legalmente.

Portanto, a sociedade deve compreender as questões legais, éticas e socioeconômicas que envolvem a informação e a tecnologia (indicador de desempenho 5.1), entender as questões ligadas ao direito nacional e internacional de propriedade intelectual e as leis de imprensa (resultados desejáveis 5.1.2), cumprir as leis, regulamentos, políticas institucionais e normas relacionadas ao acesso e uso às fontes de informação (indicador de desempenho $5.2)$.

Todos estes indicadores contribuem para as ações à medida que reforçam o pensamento racional, reflexivo e crítico mediante o acesso efetivo de informações disponibilizadas pelas TIC e em rede dentro de espaços de intercâmbio e participação por meio do fomento de práticas pedagógicas e informacionais, tendo como base a filosofia da educação para todos. Assim, há o estabelecimento de estreita relação entre as bibliotecas e as escolas, mediante trabalho integrado e conjunto, com o intuito de promover a leitura e a pesquisa.

Essas ações promovidas pelos padrões, indicadores de desempenho e resultados desejáveis do cidadão competente em informação e em mídia estão imersas em um contexto de desafio no Brasil, conforme explica Camargo (2017) existem vários desafios no Brasil em relação à cidadania, mesmo com as conquistas posteriores ao governo militar. Um dos problemas do país é que ainda existem milhões de pessoas na miséria, índices de desemprego elevados, taxa alta de analfabetos e semianalfabetos, além do drama de vítimas de violência particular e oficial (CAMARGO, 2017). Além disso, o desenvolvimento dos contextos locais e públicos está diretamente relacionado com as desigualdades regionais e culturais. Assim, cabe a cada município manejar vários tipos de informação, atuar em diferentes dimensões, reunir espaços dispersos e verificar a rentabilidade dos novos projetos públicos (HOLANDA; OLIVEIRA; OLIVEIRA, 2013). 
Além disso, a cultura do segredo ainda é muito forte nas organizações públicas brasileiras, o que dificulta a obtenção dessas informações. Muitos são os obstáculos a vencer, tais como o tempo de espera da entrega das informações, má construção nos sites do governo, conhecimentos prévios de como manusear estes sites, entre outros problemas. Complementando, Holanda, Oliveira e Oliveira (2013) a discussão da informação é fundamental, pois é um recurso de poder da sociedade tendo em vista que a criação de conhecimento ocorre por meio do acesso à educação e informação.

Devido a esse espectro de dificuldades, acredita-se que a Competência em Informação é elemento transformador, pois os indivíduos competentes em informação se tornam capazes de avaliar a esfera pública de maneira eficaz. O uso da informação estimula os indivíduos a participar ativamente da sociedade democrática e com isso, exercer o seu papel de cidadão. As TIC facilitaram o uso da informação por parte do cidadão, principalmente pelo acesso aos sites governamentais. $\mathrm{O}$ indivíduo pode obter dado e informações de maneira mais rápida e com um custo mais baixo.

Frey (2002) corrobora ao declarar que independente da TIC que os países possuem e de sua velocidade, o sucesso para acesso à informação e a apropriação dessas informações que tornam os cidadãos cada vez mais capacitados em sua tomada de decisão com base na compreensão crítica e igualitária do contexto, depende exclusivamente das decisões políticas e econômicas que o país realiza, porque são os agentes públicos que regulamentam e disponibilizam o acesso aos seus portais/e-governança, e ainda a respeito dessa afirmação o autor cita três campos de ação:

1) Pontos de acesso público, quiosques interativos onde os cidadãos têm acesso gratuito à Internet são de importância fundamental para garantir que todas as pessoas tenham pelo menos a chance de usar as novas tecnologias e os serviços online, ou participar de fóruns de discussão pública. [..]

2) Campanhas de ensino da linguagem digital são também de importância fundamental para capacitar os cidadãos a usarem a Internet de maneira consciente e em benefício próprio. Isso significa não apenas transmitir capacidades técnicas para o uso de computadores e da Internet, mas também seu uso de maneira a fomentar a cidadania ativa.

3) O apoio a aplicativos para a cidadania significa explorar as possibilidades da Internet para fomentar uma esfera pública virtual. O sucesso dos fóruns públicos no aprofundamento da prática democrática depende da capacidade de criar ligações entre os fóruns virtuais e o processo político tradicional de comunidades reais. Se o processo de discussão nos fóruns virtuais não tiver consequências para o processo de tomada de decisão em organizações políticas reais, a predisposição da população em participar vai logo diminuir (FREY, 2002, p. 148-149, grifo do autor).

Peci e Costa (2002) ressaltam que uma das dificuldades encontradas na implementação, desenvolvimento e alteração da política pública no Brasil é a ausência de redes inter organizacionais, pois as empresas públicas e privadas, associações, grupos de interesses, comunidades, organizações não governamentais poderiam participar ativamente

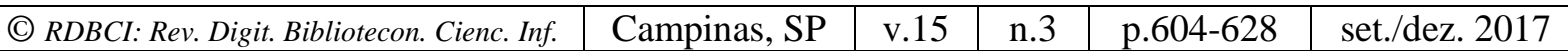


no planejamento. As redes podem se utilizar da comunicação direta e confiável como principal mecanismo integrador entre o uso e disseminação de informação, a fim de que sejam compreendidas pelo usuário (emissor e receptor) e posteriormente, convertidas e compartilhadas com significado para os envolvidos nos processos gerenciais. A informação disseminada pelo cidadão gera ações com enfoque na cooperação, planejamento, excelência no desempenho, objetivos e resultados alcançados de maneira integradora e em rede.

Concordando com Peci e Costa (2002) Börzel (1998 apud SARAIVA, 2002) ressalta que as redes no âmbito público implicam em um conjunto de conexões estáveis, não hierárquicas e interdependentes. As redes da esfera pública envolvem diferentes atores sociais que possuem interesse comum sobre determinada política. Os membros da rede reconhecem que a rede é uma ferramenta a fim de alcançar os objetivos comuns.

Passador e Ferreira (2006), também ressaltam que a centralização das decisões impede que as políticas públicas embasada nesta nova gestão "em redes", obtenham o desempenho esperado, porque ainda o Brasil necessita construir uma cidadania legítima, garantindo os direitos de sua população, participação e atuação nos processos operacionais, decisórios, reconhecendo o papel importante de implementar as políticas públicas em redes.

Além da questão da comunicação da sociedade, governo e entidades privadas para o estabelecimento de políticas públicas, Holanda, Oliveira e Oliveria (2013) apontam que os direitos adquiridos dos cidadãos necessitam ser fáceis de acessar, pois condicionam a legislação a ação social, e a teoria a prática política. Nesse sentido, os direitos sociais compreendem as noções de liberdade, igualdade e fraternidade para todas as pessoas. Tais direitos consideram as diferenças de classe, raça, etnia, gênero e estimula o exercício da cidadania de maneira igual a todos os indivíduos.

\section{CONSIDERAÇõES FINAIS}

O Brasil já desenvolveu diferentes fontes de acesso à informação pública, entretanto algumas são irregulares, pois os dados não foram processados de maneira acessível ao cidadão. Tal fato dificulta a construção de conhecimento por parte da comunidade, que muitas vezes desiste da busca. A Lei de Acesso a Informação existe, porém não há diretrizes para nortear o modo de disseminação dos dados.

Esse cenário só pode se modificar com a maior participação política do povo, sob a perspectiva de serem competentes em informação. Assim, a Competência em Informação pode contribuir com a cidadania na medida em que instiga a curiosidade dos cidadãos, propiciando o acesso à informação, a avaliação de suas fontes de maneira crítica e o uso dessa informação tanto para a reflexão quanto para a aplicação prática. 
Neste aspecto, a Competência midiática surge de maneira integrada à Competência em Informação, à medida que capacita os indivíduos para exercer o uso efetivo das TIC e das mídias, proporcionando compreensão consolidada e crítica de dados e informações; atribuindo aos indivíduos a devida responsabilidade pela produção e disseminação de informações, objetivando criar conhecimento ao receptor final (leitor/ouvinte/usuário); a comunicação ética e verídica pelos diversos meios tecnológicos e midiáticos, são responsáveis pela mudança de pensamento, posicionamento e desenvolvimento da consciência do cidadão.

A Competência em Informação e a Competência Midiática surgem como aspecto avassalador na transformação e construção de uma cidadania mais democrática e participativa, gerando no cidadão o poder de tomar decisões em fatos reais, fazer uma análise inteligente e racional, torna o indivíduo apto para relacionar os pós e os contra das situações e informações que acessam, usam, compartilham e descartam; propiciando o desenvolvimento e crescimento desses, enquanto profissionais, contribuintes, eleitores, cidadãos, emissores e receptores de informações.

A Competência em Informação e a Midiática transformam uma sociedade, uma cidade, um estado e um país, quando esse mesmo país proporciona o ambiente e os instrumentos adequados para essa equidade educacional, econômica, social, política e cultural, ele está também promovendo a sua ascensão financeira e governamental. Dispor de dados e informações valiosas para inovação, pesquisa, agilidade, qualidade, construção de conhecimento, maior performance, melhorias contínuas e crescimento produtivo, só será possível quando nossos governantes por meio da nossa democracia, mudar o seu posicionamento, enxergando seus cidadãos como instrumento de oportunidades para mudanças assertivas e efetivas, sem querer controlar e tirar proveito do seus cargos políticos, mas, sim trabalhando lado a lado para um país melhor e um futuro promissor, onde as pessoas são extremamente capacitadas, detêm o conhecimento, habilidades e empregam ações efetivas ao longo de sua vida e em todos aspectos enquanto cidadãos brasileiros e do mundo.

O uso da informação governamental de maneira inteligente influencia a participação da população na democracia, já que são cruciais para o indivíduo exercer seu poder de voto e também, monitorar os agentes públicos, projetos e programa sociais. O uso da informação de maneira inteligente consciente é influenciado pelas habilidades, capacidades e experiências dos indivíduos no que tange a participação democrática e o exercício da cidadania.

Como incentivo a pesquisas futuras indica-se pesquisas fenomenográficas, a fim de identificar a experiência da Competência em Informação de indivíduos politicamente ativos como, por exemplo, dos sujeitos que fazem parte de associações políticas e pressionam o governo, cujo intuito é o de estabelecer políticas públicas para diminuir a dominação do Estado e das organizações privadas, principalmente em uma sociedade que é baseada no sistema capitalista de produção. 


\section{REFERÊNCIAS}

AGÊNCIA DE NOTÍCIAS DOS DIREITOS DA INFÂNCIA (ANDI). Direitos de acesso à informação. 2011. Disponível em: < http://www.andi.org.br/direito-de-acesso-a-informacao >. Acesso em: 31 jul. 2017.

AKUTSU, Luiz; PINHO, José Antonio Gomes de. Sociedade da informação, accountability e democracia delegativa: investigação em portais de governo no Brasil. Revista de Administração Pública, Rio de Janeiro v. 36, n. 5, p. 723-45, set./out. 2002.

BELLUZZO, Regina Célia Baptista. Competência em informação: vivências e aprendizado. In: BELLUZZO, Regina Célia Baptista; FERES, Glória Georges (Org.). Competência em Informação: das reflexões às lições aprendidas. São Paulo: FEBAB, 2013, v. 1, p. 58- 74.

BELLUZZO, Regina Célia Baptista. Construção de mapas: desenvolvendo competências em informação e comunicação. 2. ed. Bauru: Cá Entre Nós, 2007.

BELLUZZO, Regina Célia Baptista; FERES, Glória Georges. Competência em informação, redes de conhecimento e as metas educativas para 2021: reflexões e inter-relações. In: BELLUZZO, R. C. B; FERES, G. G.; VALENTIM, Marta Lígia Pomim (Orgs.). Redes de conhecimento e competência em informação: interfaces da gestão, mediação e uso da informação/organização. Rio de Janeiro: Interciência, 2015. p.1-35.

BOCCATO, Vera Regina Casari. Metodologia da pesquisa bibliográfica na área odontológica e o artigo científico como forma de comunicação. Revista de Odontologia da Universidade da Cidade São Paulo, São Paulo, v. 18, n. 3, p. 265-274, 2006.

BRADLEY, Cara. Information literacy policy in Canada: is it time? Partnership: the Canadian Journal of Library and Information Practice and Research, v. 8, n. 2, p. 1-28, 2013.

BRAGA, Marcus Vinícius de Azevedo. A auditoria governamental como instrumento de promoção da transparência. In: CONGRESSO DE GESTÃO PÚBLICA CONSAD. 4. , Brasília, Distrito Federal. p. 3-20, 2011.

CAMARGO, Orson. O que é cidadania? Brasil Escola. Disponível em: < http://brasilescola.uol.com.br/sociologia/cidadania-ou-estadania.htm >. Acesso em: 18 jan. 2017.

CARVALHO, Ângela Maria Grossi de. A apropriação da informação: um olhar sobre as políticas públicas sociais de inclusão digital. 2010. 169 f. Tese (Doutorado em Ciência da Informação) - Universidade Estadual Paulista "Júlio de Mesquita Filho" Faculdade de Filosofia e Ciências. Marília, 2010.

CASARIN, Helen de Castro. Competência informacional e midiática e a formação de professores de ensino fundamental: um relato de experiência. Revista Brasileira de Biblioteconomia e Documentação, São Paulo, v. 13, n. especial, p. 301-321, jan./jul. 2017. Disponível em: < https://rbbd.febab.org.br/rbbd/article/view/649/578>. Acesso em: 11 maio 2017.

\begin{tabular}{l|l|l} 
v.15 & n.3
\end{tabular}
p.604-628 set./dez. 2017 
CONTROLADORIA GERAL DA UNIÃO. Acesso à informação pública: uma introdução à Lei 12.527, de 18 de novembro de 2011. Brasília: Distrito Federal, 2011. Disponível em: < http://www.acessoainformacao.gov.br/central-deconteudo/publicacoes/cartilhaacessoainformacao.pdf >. Acesso em: 24 de jul. 2014.

DE FARIAS, Gabriela Belmont. Competência informacional e midiática no ensino de biblioteconomia: apontamentos para o contexto brasileiro. Revista Brasileira de Biblioteconomia e Documentação, v. 13, p. 111-135, 2017.

FREY, Klaus. Governança eletrônica: experiências de cidades europeias e algumas lições para países em desenvolvimento. In: EISENBERG, José.; CEPIK, Marco (org.). Internet e política: teoria e prática da democracia eletrônica. Belo Horizonte: UFMG, 2002. p. 141-163, 2002.

GIL, Antonio Carlos. Métodos e técnicas de pesquisa social. 6. ed. São Paulo: Atlas, 2008.

GOMES, Cristiana. Democracia. 2006-2017. Disponível em: < http://www.infoescola.com/sociologia/democracia/ >. Acesso em: 23 jan. 2017.

HABERLE, Peter. A. Dignidade humana e a democracia pluralista: seu nexo interno. In: SARLET, Ingo Wolfgang (Org.). Direitos fundamentais, informática e comunicação: algumas aproximações. Porto Alegre: Livraria do Advogado, 2007. p.11-28.

HOLANDA, Adriana Buarque de.; OLIVEIRA, Maria Cristina Guimarães.; OLIVEIRA, Simone Rosa de. Incentivo a cultura: experiências brasileiras de políticas públicas interesses da área da ciência da Informação. Transinformação, Campinas, v. 25, n. 1., jan./abr., 2013.

NORRIS, Pippa. Digital divide: civic engagement, information: poverty and the internet in democratic societies. New York: Cambridge University Press, 2001.

ORGANIZAÇÃO DAS NAÇÕES UNIDAS PARA A EDUCAÇÃO, A CIÊNCIA E A CULTURA (UNESCO). Alfabetização midiática e informacional (AMI). 2017. Disponível em: < http://www.unesco.org/new/pt/brasilia/communication-and-information/access-toknowledge/media-and-information-literacy/ >. Acesso em: 31 jul. 2017.

OTTONICAR, Selma Letícia Capinzaiki.; FERES, Glória George. Information Literacy in Brazil. In: EUROPEAN CONFERENCE ON INFORMATION LITERACY. Springer International Publishing, 2014, p. 743-751.

PASSADOR, C. S.; FERREIRA, V. R. S. Produção acadêmica sobre redes no Brasil. In: SIMPÓSIO DE GESTÃO DE INOVAÇÃO TECNOLÓGICA DA ASSOCIAÇÃO NACIONAL DE PÓS GRADUAÇÃO E PESQUISA EM ADMINISTRAÇÃO, 24. Gramado: out. 2006. Anais...

Disponível em: < http://www.anpad.org.br/diversos/trabalhos/Simp\%C3\%B3sio/simposio_2006/DCT/2006_D CT970.pdf >. Acesso em: 30 mar. 2017. 
PECI, Alketa; COSTA, Frederico José Lustosa da. Redes para implementação de políticas públicas: obstáculos e condições de funcionamento. In: ENCONTRO DA ASSOCIAÇÃO NACIONAL DE PÓS-GRADUAÇÃO EM ADMNISTRAÇÃO, 26, 2002, Salvador, p. 1-15.

SARAIVA, Enrique. Redes, organizações em rede e organizações virtuais: as novas configurações organizacionais. Revista Portuguesa e Brasileira de Gestão, Rio de Janeiro: FGV/EBAPE, v. 1, n. 1, p. 18-23, abr./jun. 2002.

SILVA, José Afonso da. Princípios constitucionais fundamentais. In: 20 ANOS DA CONSTITUIÇÃO CIDADÃ; CADERNOS ADENAUER, 9, 2008, Rio de Janeiro: Fundação Konrad Adenauer, v. 1, p. 12-14.

WILSON, Carolyn; GRIZZLE, Alton; TUAZON, Ramon; AKYEMPONG, Kwame; CHEUNG, Chi-kim. Alfabetização midiática e informacional: currículo para formação de professores. Brasília: UNESCO, UFTM, 2013. Disponível em:

< http://unesdoc.unesco.org/images/0022/002204/220418por.pdf >. Acesso em: 30 mar. 2017.
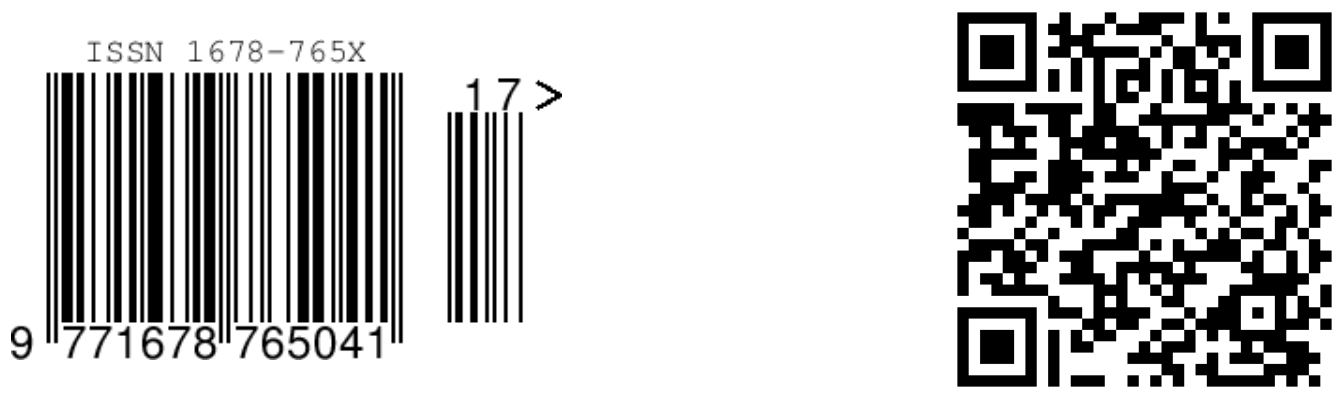